\title{
Terceiro setor, teoria das organizações e qualidade na educação
}

\author{
Marilda de Oliveira Costa*
}

\section{Resumo}

Este artigo é parte de estudos realizados no doutorado em Educação e tem por objetivo discutir a qualidade da educação apresentada nos materiais instrucionais de uma entidade do Terceiro Setor que tem influenciado políticas educacionais de diferentes esferas de governo desde finais da década de 1990 no Brasil. É de abordagem qualitativa e constou de análise de documentos expedidos pela referida entidade e pelo poder público de um município brasileiro. A ideia de qualidade veiculada nesses materiais é tomada de empréstimo das teorias das organizaçóes empresariais, como a Gerência da Qualidade Total. Atualmente, tem se evidenciado que a polissemia de ideias envolvidas no termo qualidade da educação possibilita diversas interpretaçóes e facilita os discursos ou slogans sobre a temática. Apesar da relevância desses discursos, os materiais analisados mostram que a defesa da qualidade tem se dado no plano discursivo ou em slogans, como um recurso de poder, sem uma definição clara e objetiva da qualidade que se defende para a educação brasileira.

Palavras-chave: Terceiro Setor. Administração da Educação. Qualidade Total.

\footnotetext{
* Doutora em Educação pela Universidade Federal do Rio Grande do Sul (UFRGS). Professor titular da Universidade do Estado de Mato Grosso (UNEMAT), campus de Cáceres.
} 


\section{Introdução}

Nos últimos tempos, tornaram-se hegemônicos os discursos sobre qualidade da educaçáo. Das conversas de bar ao meio acadêmico, dos organismos multilaterais ao ambiente empresarial e agendas políticas governamentais, todos defendem a qualidade da educação. Nota-se que os discursos subjacentes a esses meios apresentam uma variedade de definiçóes próximas do lugar sóciohistórico de cada um desses sujeitos sociais. Parece que a polissemia de ideias relacionadas ao termo tem possibilitado uma variedade de opinióes envolvendo a temática, em sua maioria, muito próximas da ideia de qualidade defendida para o meio empresarial.

A transposiçáo do conceito de qualidade do mercado para a área educacional pode estar relacionada com o esgotamento do modelo de acumulação fordista-keynesiano, passando-se para o modelo de acumulação flexível (HARVEY, 2003) a partir dos anos 1970 e com a alternativa encontrada pelo mercado para dar vazão a seus produtos em momentos de crise de acumulação capitalista. Esse contexto é marcado por um conjunto de profundas mudanças em diversas áreas que afetaram diretamente as formas de organização da vida em sociedade, incluindo-se a administração da educação. O momento é marcado pela reestruturaçáo produtiva e pela ideia de "qualidade total" a ela subjacente.

As medidas neoconservadoras orientaram a reestruturação do Estado, alterando seu papel, de modo a afetar grandemente a ideia de público estatal e a área social. As ações do Estado são orientadas pelos parâmetros da macroeconomia, atingindo diretamente as políticas sociais. Inauguram-se novas e complexas formas de financiamento e execução dessas políticas, entre as quais as de saúde e educação. Em inúmeros países de todos os continentes, o Estado passou a não mais executá-las diretamente - ou transfere a oferta dessas políticas para o mercado, por meio das privatizaçóes, ou financia o setor privado para a oferta e gestão. Emergiram, nesse contexto, formas de execução de políticas que extrapolaram a simples privatizaçâo ou mesmo a delimitaçấo de fronteiras entre a esfera pública e a privada (DALE, 1995). A criação da figura jurídica público não estatal possibilitou incursóes de um novo ator nessa relação: o Terceiro Setor.

Cabe advertir que o Terceiro Setor ao qual me refiro neste texto náo se relaciona com entidades como as organizaçóes não governamentais identificadas 
com as lutas políticas no continente latino-americano contra as ditaduras militares nas décadas de 1970 e 1980, sucessivamente. Trata-se de um Terceiro Setor em substituição ao papel do Estado, a partir da década de 1990. No caso em estudo, é um setor que mantém estreita relação com o grande capital e, em consonância com as prerrogativas do mercado, elabora políticas educacionais, induz parcerias com o setor público, acompanha, controla os resultados da educação pública por meio de sistemas de avaliação externa, sistemática de acompanhamento e inserção de informaçóes em tempo real em sistema informatizado de informação, compreendido também como um sistema de gestão da qualidade da educação (IAS, 2007).

Com base em algumas categorias selecionadas para a análise, defendo neste texto que a ideia de qualidade da educaçáo observada em teorias como aquelas que fundamentam os princípios da Gerência da Qualidade Total (GQT), de base epistemológica e do meio empresarial, foi identificada nos materiais de gestão municipal e escolar do Instituto Ayrton Senna - IAS, entidade do Terceiro Setor, que, com a justificativa de promover a qualidade da educação, induz parcerias e implementa seu projeto de educaçáo nas diferentes esferas de governos das cinco regióes brasileiras.

\section{Instituto Ayrton Senna - Uma entidade do Terceiro Setor emergente}

A emergência e a difusão do termo "Terceiro Setor", conforme acepção do co-diretor do Comitê Executivo de Civicus, Miguel Darcy de Oliveira, podem ser consideradas recentes. O termo foi difundido nos anos 1990, com a criação da Aliança Mundial para a Participação dos Cidadãos - Civicus, lançada em 1993, como "[...] uma das primeiras tentativas de criar uma instituição especificamente voltada para a promoçâo da cidadania ativa e da sociedade civil em escala mundial" (OLIVEIRA, 1994, p. 11). Segundo Oliveira, trata-se de um Terceiro Setor " $[. .$.$] não-lucrativo e não-governamental - coexiste hoje, no$ interior de cada sociedade, com o setor público estatal e com o setor privado empresarial" (OLIVEIRA, 1994, p. 11).

O termo foi apresentado no Brasil por ocasião da realização do III Encontro Ibero-Americano do Terceiro Setor, realizado em setembro de 1996 no Rio de Janeiro. Nesse encontro, discutiram-se o seu conceito, suas formas e limites (IOSCHPE, 2005). De modo geral, o grupo reunido no seminário 
defendeu a atuação de um "Terceiro Setor" em substituição ao papel do Estado. Não por acaso, era um momento de intensa reforma administrativa no papel do Estado no Brasil, com alteraçóes que atingiram a propriedade do que continuaria público, de responsabilidade direta do Estado e o público não estatal, delineando as funçóes que poderiam ser financiadas pelo Estado, mas executadas pelo Terceiro Setor. O crescimento do referido setor, no Brasil, a partir da reforma do Estado, é emblemático. Um levantamento do IBGE datado de 2005, realizado em parceria com o IPEA e a Abong, constatou a existência de 338 mil organizaçôes sem fins lucrativos no Brasil.

Segundo Antunes (2003, p. 115), "[...] o terceiro setor compóe-se de formas de trabalho comunitário e assistencial que se expandem prioritariamente numa fase de desmonte do Estado do bem-estar social, tentando suprir em parte aquelas esferas de atividade que eram anteriormente realizadas pelo Estado".

Para este autor o crescimento desse setor "[...] decorre da retração do mercado de trabalho industrial e também da redução que começa a sentir o setor de serviços, em decorrência do desemprego estrutural" (ANTUNES, 2003, p. 112). Em verdade, ele é "[...] conseqüência da crise estrutural do capital, da sua lógica destrutiva vigente, bem como dos mecanismos utilizados pela reestruturação produtiva do capital visando reduzir trabalho vivo e ampliar trabalho morto" (ANTUNES, 2003, p. 112).

Nesse contexto, a retração no papel do Estado para a provisão de direitos sociais também é visível, trazendo sérias implicaçôes para a ampliação de um regime democrático no qual os interesses da coletividade (o público) sobreponham os interesses egoístas do livre mercado e da competição (privado).

No período de auge da criação e ampliação do Terceiro Setor no mundo e no Brasil, surge o Instituto Ayrton Senna, uma organização não governamental, sem fins lucrativos, fundada em novembro de 1994. Foi criada pela família do piloto de Fórmula 1 Ayrton Senna, após sua morte, nesse mesmo ano. É presidida por sua irmã, Viviane Senna, diretora da entidade desde sua fundação, e por um Conselho Consultivo formado por pessoas de diferentes segmentos ${ }^{1}$.

De acordo com Adriáo e Peroni (2010), o IAS se declara de caridade, assume compromissos com a diminuição da pobreza e com a atuação nas áreas de saúde e educação, além de mencionar a religião. Sobrevive basicamente de doaçôes da Ayrton Senna Foundation Ltda., da qual é acionista, e sua principal 
atuação refere-se à gestão da marca Senna. Segundo as autoras, a Fundação doou ao IAS, em 2007, algo em torno de 145.898 euros em valores de 31 de dezembro do mesmo ano. Além dessas fontes, o IAS ainda conta com recursos provenientes da venda dos produtos licenciados com a marca Senna, da doação de pessoas, de recursos de alianças estratégicas com empresas, ${ }^{2}$ como a doação de $\mathrm{R} \$ 4$ milhôes, ${ }^{3}$ recebida pelo IAS, em apenas 30 minutos, no $7^{\circ}$ Fórum de Líderes Empresariais (LIDE), realizado em Comandatuba-BA no mês de maio de 2008, e ainda outros recursos, provenientes de parcerias, como aquela realizada em 2009 com o Ministério da Educaçáo para disseminar suas tecnologias para os municípios por um período de 18 meses, a partir da assinatura do convênio no valor R\$31.502.138,00, pagos pelo FNDE (GUTIERREZ, COSTA, 2011). Recursos indiretos para atender aos programas do IAS são gastos por seus parceiros do poder público, decorrentes da compra de materiais didáticos de firmas contratadas pelo IAS, entre elas, a Editora Global, e prestação de serviços de assessoria. Até mesmo empresas públicas como a Petrobrás e a Fundação Banco do Brasil, entre outras, apoiam o trabalho dessa ONG.

Informaçóes no $s i t e^{4}$ do Instituto apontam que a sua "[...] meta principal tem sido trabalhar para criar oportunidades de desenvolvimento humano a crianças e jovens brasileiros, em cooperação com empresas, governos, prefeituras, escolas, universidades e ONG’s [...]". Tem como missão “[...] contribuir para a criação de condiçóes e oportunidades para que as crianças e todos os adolescentes brasileiros possam desenvolver plenamente o seu potencial como pessoas, cidadãos e futuros profissionais" (IAS, 2005), acreditando que a transformação do País passa pela corresponsabilidade de três setores: organismos governamentais, empresas e organizaçóes da sociedade civil, que devem desenvolver políticas públicas que favoreçam crianças e adolescentes.

Entre os programas de educaçáo formal desse instituto implementados pelo Poder Público, encontram-se o Programa de Gestão Municipal e Escolar, Escola Campeá - PEC (2001 a 2004) e o Gestão Nota 10 (2005 até os dias atuais), integrante da Rede Vencer. Informações detalhadas desses programas poderão ser encontradas em Costa (2011).

O Programa Escola Campeã (2001-2004) objetivava “[...] a melhoria na qualidade da educaçáo e o sucesso do aluno [...]" (IAS, 2001), propondo metodologias voltadas para o fortalecimento "[...] da gestáo ligada às secretarias municipais de educação e o gerenciamento das unidades escolares do ensino fundamental municipal [...]” (IAS, 2001). 
O Programa foi estruturado para ser desenvolvido em quatro anos, de 2001 a 2004, e a base de sua proposta foram açóes de fortalecimento da gestáo municipal e da gestão escolar, com vistas a uma gestão municipal eficiente. Para o cumprimento das metas desse modelo de gestão, estabeleceram-se como estratégias a instituição de avaliação externa de desempenho de alunos do Ensino Fundamental, as avaliaçóes dos indicadores de gestão (22 indicadores) e de eficiência (21 indicadores), e a implementação de um sistema informatizado de gestão educacional (BAHIA, 2000).

A Rede Vencer foi instituída no início do ano de 2005 com a função de integrar os diferentes municípios brasileiros parceiros do IAS. Quatro programas de educação formal integram essa rede: o Gestão Nota 10, que veio substituir o PEC, os de correçáo de fluxo - Se Liga e Acelera Brasil - e um novo programa, o Circuito Campeão. Segundo o IAS (http://www.senna.globo.com/ institutoayrtonsenna. Acesso em 29.05.2010), os programas da área concebem a gestáo como a articulaçáo entre recursos e conhecimentos, e valem-se de processos e ferramentas gerenciais tanto para superar problemas já existentes quanto para evitar que estes se instalem nas redes de ensino. A instituiçáo desses programas justifica-se, segundo o próprio Instituto, porque este

[...] assumiu a promoçáo do desenvolvimento humano da nova geração através da educação, com a missão de construir e disponibilizar tecnologias sociais a governantes que queiram 'fazer a diferença' em seus estados e municípios, pelo desenvolvimento cognitivo, afetivo e social das crianças (IAS, 2005, p. 1).

Análogo ao PEC, os convênios entre a Rede Vencer e o poder público abrangem uma gestão municipal e/ou estadual, ou seja, têm duração de quatro anos, e justificam-se pela ideia de defesa da "[...] causa do desenvolvimento integral das novas geraçóes, através da qualidade da aprendizagem no Ensino Fundamental nas escolas públicas" (IAS, 2005, p. 1).

As incursôes do IAS na área educacional são justificadas sob os argumentos da ineficácia do Estado em promover uma educação de qualidade, e de desperdício de dinheiro público com a evasão e repetência.

A partir da década de 1990, no Brasil, o acesso ao Ensino Fundamental alcançou quase $100 \%$ das crianças em idade escolar; no entanto, a problemática hoje gira em torno da qualidade da educaçáo. Se o Estado é ineficiente nessa 
função, como assinalam discursos do mercado e de segmentos como o Terceiro Setor, a questão seria: que ideia de qualidade defende o IAS? De fato, os materiais instrucionais do IAS apresentam um conceito de qualidade da educação, ou esta não passa de um slogan utilizado por ele para difundir seus próprios interesses e os do capital na educação? Em que medida os argumentos em defesa da qualidade da educação se relacionam com aqueles provenientes do meio empresarial? Para responder essas e outras questôes, trato a seguir de alguns conceitos provenientes da Gerência da Qualidade Total e de sua aproximaçấo com um conjunto de ideias apresentadas nos materiais de gestão do IAS, que, segundo afirmam, conduzem à qualidade da educação.

\section{Gerência da Qualidade Total nas organizações e qualidade da educação}

A abordagem da Qualidade Total nas organizaçóes está intimamente associada à crise estrutural do capital, com a queda de lucro das empresas a partir dos anos de 1970. É no contexto de reestruturação produtiva, de mudanças no padrão de organização e gestáo dos processos produtivos e do trabalho, inclusive nas organizaçóes educacionais orientadas pela ideologia neoliberal e nas metamorfoses no papel do Estado capitalista, que faz sentido tratar essa abordagem. Conceitos nela contidos, como qualidade, controle, liderança, objetivos, metas, racionalidade, trabalho em equipe ou time, participação, cooperação, gerência, parceria, terceirização e alianças ou aliados estratégicos fazem parte do vocabulário do Instituto Ayrton Senna e de seus Programas de gestão da educação escolar.

Conceitos tratados em outras abordagens das teorias das organizaçóes, como liderança, gerência, metas, racionalidade, controle e cooperação, entre outros, são readaptados e aparecem compondo o quadro de referência da literatura sobre a GQT, neste momento de reestruturação produtiva, confirmando a constatação de Félix (1989) sobre essa questão. Na evolução das teorias da administração, segundo ela, "[...] não se dá a total substituição das concepçóes de cada escola. O que se observa, pelo contrário, é a integração das concepçóes das diferentes escolas e a sua aplicação na organização do trabalho e da produçáo nas empresas capitalistas" (FÉLIX, 1989, p. 53). Como a área da Administraçáo Educacional, exceto a gestáo democrática, historicamente foi uma adaptação da área empresarial, as afirmações de Félix 
parecem fazer sentido também para a referida área, conforme constatei no objeto em foco nesta análise.

A relevância dessa abordagem se dá por pelo menos dois motivos: a possibilidade de esclarecer a forma como a GQT é providencial à nova organização do capitalismo mundial e a possibilidade de se fazerem as analogias acima anunciadas entre muitos conceitos nela contidos e aqueles difundidos pelo IAS.

Cabe esclarecer, em primeiro lugar, que as bases que dão sustentação à GQT, como aquelas provenientes da teoria sistêmica das organizaçóes, partem também de abordagens sistêmicas. $\mathrm{Na}$ abordagem dos sistemas complexos, Leff atribui ao conhecimento sentido diverso do pensamento dominante, o qual compreende uma "[...] complexidade do mundo, um saber sobre as formas de apropriação do mundo e da natureza, através das relaçóes de poder que têm sido inscritas nas formas dominantes do conhecimento" (LEFF, 2004, p. 16). É com essa lupa que pretendo olhar o conhecimento complexo cujas bases sustentam a GQT.

Já que ideias contidas nas abordagens sistêmicas ajudam a compreender as bases epistemológicas da Qualidade Total, começo então com uma breve definição delas, tendo por base texto de Evando Neiva (1996), difundido no IV Congresso Pitágoras, Qualidade em Educação, além de autores como Capra e Morin, que tratam da abordagem científica sobre a qual se sustenta a GQT.

Para conseguir os meios intelectuais e conceptuais para entrar no universo da complexidade, Morin afirma que precisou esperar pelos anos de 1950 e pela chegada de três "teorias novas" - a Teoria dos Sistemas, a Cibernética e a Teoria da Informação (MORIN, 1998). Igualmente, as bases da Gerência de Qualidade Total parecem encontrar-se no pensamento complexo: na Física moderna, na Ciência do Caos e na Teoria de Prigogin, com o estudo da evolução dos sistemas complexos, tendo em vista a sua interação com o ambiente (NEIVA, 1996).

No tocante à Física moderna, a insuficiência dos conceitos clássicos para descrever os fenômenos atômicos levou os físicos quânticos a compreenderem que o princípio de que as partículas são "coisas" isoladas é uma ilusão. Capra (2006) afirma que para David Bohm, na Teoria Quântica, nunca lidamos com "coisas", lidamos com interconexôes. Assim sendo, o funcionamento do mundo que nos rodeia pode ser apreendido sem "conflitos e confusóes intermináveis" (NEIVA, 1996, p. 97). 
A teoria quântica mostrou que as partículas subatômicas não são grãos isolados de matéria, mas modelos de probabilidades, interconexôes numa inseparável teia cósmica que inclui o observador humano e sua consciência. Pode ser também denominada visão sistêmica, no sentido da teoria geral dos sistemas. (CAPRA, 2007, p. 72).

Em contraste, para a Física Clássica, que prevaleceu até o final do século XIX, as partículas poderiam ser estudadas isoladamente, com seu comportamento totalmente previsível a partir das condiçóes iniciais, tais como: posição, velocidade e forças atuantes. Segundo Neiva (1996, p. 78), esses “[...] dois paradigmas científicos podem ser associados, por uma estreita analogia, com a evoluçáo dos paradigmas gerenciais das organizaçóes, do século XIX para o século XX". O autor estabelece relaçáo entre o modelo anterior, que tinha organização pautada nas formas hierárquicas e as funçôes individuais bem definidas, com pouca interação externa e com a gerência baseada no controle. No paradigma atual, "[...] que tem por base os princípios da Qualidade Total, a organização é articulada e aberta, interna e externamente, o foco é no trabalho cooperativo, em times, e, em lugar do controle, temos o autogerenciamento" (1996, p. 78).

Outras analogias ainda são feitas pelo autor ao tratar das conclusões científicas da Física moderna, como entre a natureza dual das partículas, que ao mesmo tempo são individualidade e interconexóes, e os conceitos de energia pessoal - empowerment - e de sinergia, utilizada na Qualidade Total. Nessa perspectiva, Neiva destaca duas contribuiçôes complementares do sujeito na organização: "[...] pela sua energia pessoal - individualidade -, ela [a sinergia] deve exercer a autoinspeção e o autocontrole; pela sinergia - interconexão -, ela deve atuar cooperativamente, participando de times de trabalho e agindo de forma articulada com os diversos setores da organização" (NEIVA, 1996, p. 78).

Outra área da ciência - a Ciência do Caos - é também tratada por Neiva (1996) para aproximar alguns conceitos dessa área com a Qualidade Total. Segundo ele, "[...] a Ciência do caos tem como objeto o estudo dos sistemas complexos, entendendo por sistemas complexos aqueles formados por uma infinidade de interconexóes" (NEIVA, 1996, p. 78). Não cabe aqui destacar novamente alguns conceitos constitutivos da concepçáo sistêmica, mas ver suas proximidades com a Qualidade Total. Nesse sentido, conforme a Ciência 
do Caos, o comportamento de um sistema complexo, embora imprevisível, tem uma "[...] dependência sensível das condições iniciais" (CAPRA, 2007, p. 86). Ou seja, qualquer perturbação no sistema - alteração das suas condiçôes iniciais - tem consequências significativas. Igualmente, o comportamento de um sistema complexo, embora imprevisível, fica dentro de limites, e seu contorno recebe o nome de "atrator estranho" (CAPRA, 2007, p. 86). Da mesma forma, "[...] o formato desse atrator estranho depende dos parâmetros do sistema e, é claro, de suas condiçóes iniciais" (NEIVA, 1996, p. 79).

A analogia com a Gerência da Qualidade Total parece encontrar-se na missão ou na razão de ser da GQT, na definição da visão e das metas, e na expressão de um conjunto de valores. Tudo isso, segundo Neiva, compartilhado por todos os que integram a organizaçáo, como uma iniciativa da liderança. Neiva (1996, p. 80) afirma que, "Identificamos nesses elementos a definiçẫo de parâmetros e das condiçóes iniciais para que a complexidade que representa a organização possa evoluir, embora de forma não-linear (imprevisibilidade), para uma ordem superior, dentro de limites previsíveis (atrator estranho)" (NEIVA, 1996, p. 80).

O papel atribuído à liderança perpassa todo o material instrucional do IAS, e as atribuições a ela sugeridas parecem muito próximas dessa definição da GQT. Cabe ao líder articular, na unidade escolar, os diferentes sujeitos, professores, pais, comunidade externa, empresários em busca de parcerias e do trabalho voluntário, necessárias, segundo o instituto, ao funcionamento da instituição educativa, seja do ponto de vista pedagógico, seja do ponto de vista financeiro ou estrutural. Cabe, portanto, ao diretor líder articular a participação de todos os segmentos apontados.

A evolução das estruturas para uma ordem superior também foi focalizada em estudos do físico-químico Iliá Prigogin ${ }^{5}$ sobre a evolução dos sistemas complexos - estruturas -, levando-se em conta sua interação com o ambiente. Falando de outra forma, mas com mesmo sentido aplicado à análise de sistemas fechados e abertos das organizaçóes, em Prigogin uma estrutura fechada ou não dissipativa é aquela que não interage com o ambiente que o rodeia. Tal estrutura, funcionando dessa forma, tende à entropia, ou seja, um aumento da desordem, tendendo, portanto, ao caos. Esse evento no ambiente das organizaçóes, segundo Neiva (1996), representa a possibilidade, reiteradamente, da ocorrência de declínio e extinção. 
Dadas as características dos sistemas abertos, sua interação com o ambiente, Prigogin pondera que as estruturas dissipativas poderão levar a uma ordem superior, vencendo a entropia, ou seja, a desordem. Segundo o autor, elas "[...] exibem a dinâmica da auto-organização em suas formas mais simples, manifestando a maioria dos fenômenos característicos da vida - auto-renovação, adaptação, evolução e até formas primitivas de processos 'mentais'” (CAPRA, 2007, p. 265).

Outros conceitos tratados nessa teoria são liberdade e coerência, que em si parecem contraditórios. A conciliação desses dois elementos, segundo Neiva (1996), é papel decisivo da liderança, e assim a organização pode transformarse - pela qualidade -, mantendo a sua identidade, assumindo formas mais complexas, flexíveis e ordenadas.

Neiva identifica, na Teoria de Prigogin, estreita relação com os princípios da GQT, tais como: empowerment (autoinspeção e autocontrole), sinergia (trabalho cooperativo, trabalho em times), parceria (terceirização, alianças estratégicas) e missão/visão organizacional, entre outros (NEIVA, 1996).

De posse dessas informaçôes, é possível avançar na compreensão da Qualidade Total nas organizaçóes. A Gerência da Qualidade Total é um sistema gerencial que inclui toda a organizaçáo para o encantamento do cliente, através do planejamento, do controle e do melhoramento contínuo da qualidade (GOMES, 1996; CHIAVENATO, 2003). Trata-se de um modelo de administraçáo implantado nas organizaçóes empresariais visando ao alcance da qualidade e rentabilidade de seus produtos.

Estruturada e aperfeiçoada no Japão pela JUSE (Union of Japanese Scientists and Engineers), a GQT é conceituada por Barbosa (1994) como "[...] um sistema administrativo baseado no engajamento ativo de todos os profissionais de todos os setores da instituiçáo, em atividades de controle da qualidade por toda a organização, através de métodos e técnicas específicas" (BARBOSA, 1994, p. 3).

A partir de ideias norte-americanas introduzidas no Japão após a Segunda Guerra Mundial, esse sistema é conhecido por TQC - Total Quality Control. O breve histórico da GQT apresentado pelo autor citado é claro ao mostrar que, nos momentos de crise do modelo de produção capitalista, novas alternativas administrativas compostas por velhos elementos são experimentadas, como ocorreu no caso japonês. Naquele país, a introdução da GQT corresponde 
a uma época em que os seus produtos industriais eram tidos como "lixo" no exterior, no caso, de baixa qualidade e pouco rentáveis, bem como num contexto de grande necessidade de reconstrução nacional e retomada econômica após a II Guerra Mundial (BARBOSA, 1994). O autor ressalta que foi graças à implantação da GQT, modelo de administração pautado na qualidade total, que os produtos japoneses foram altamente valorizados pela sua qualidade $\mathrm{e}$ avançada tecnologia (BARBOSA, 1994).

A difusão da GQT em outras partes do mundo, especialmente nos Estados Unidos, relaciona-se a um momento de profunda crise de produção, com a mudança no regime de acumulação capitalista fordista-keynesiano para o de acumulação flexível, conforme descrito por Antunes:

$\mathrm{Na}$ fase de intensificaçáo da taxa de utilização decrescente do valor de uso das mercadorias (Mèszáros, 1995: cap. $15 \mathrm{e}$ 16), necessário para a reposição do processo de valorização do capital, a falácia da qualidade total, táo difundida no mundo empresarial moderno, na empresa enxuta da era da reestruturação produtiva, torna-se evidente: quanto mais "qualidade total" os produtos devem ter, menor deve ser seu tempo de duração. (ANTUNES, 2003, p. 50, grifos do autor).

A Qualidade Total é o modelo administrativo providencial ao acúmulo de capital no contexto de acumulação flexível. Em tempos de reestruturação produtiva, Harvey (2003, p. 148) reconhece que "[...] a acumulação flexível foi acompanhada na ponta do consumo, portanto, por uma atençáo muito maior às modas fugazes e pela mobilizaçáo de todos os artifícios de induçáo de necessidades e de transformação cultural que isso implica”. Mudanças muito significativas na passagem do fordismo para a acumulação flexível são também registradas pelo autor. Segundo afirma, "[...] a estética relativamente estável do modernismo fordista cedeu lugar a todo fermento, instabilidade e qualidade fugidias de uma estética pós-moderna que celebra a diferença, a efemeridade, o espetáculo, a moda e a mercadificação de formas culturais" (HARVEY, 2003, p. 148).

O Brasil não ficou imune a essas transformações do mundo capitalista. Aqui, a implantação da GQT também está relacionada à crise econômica. Neste país, ela foi introduzida de forma sistemática pela Fundação Christiano 
Ottoni, Faculdade de Engenharia da Universidade Federal de Minas Gerais, com o objetivo de "[...] ajudar as indústrias brasileiras a enfrentarem a crise econômica nacional e a competitividade internacional" (BARBOSA, 1994, p. 4) na metade da década de 1980. Na área educacional, por sua vez, a GQT emerge no contexto das profundas mudanças introduzidas pelo discurso neoliberal em educação nas décadas de 1980 e 1990.

A divulgação das ideias doutrinárias da GQT no Brasil ficou sob a tutela do próprio Ministério da Educação (MEC), conforme registro de Silva (1996). Tais ideias foram resgatadas por Dias (2000) ao tratar do Programa "Escola de Qualidade Total", apresentado pelo MEC. Segundo a autora, esse programa é baseado nos princípios de Glasser, difusor das ideias de Deming no campo educacional. O Método Deming de Administração, notável "Método dos 14 pontos", foi traduzido para os meios escolares por Glasser em sete pontos, quais sejam: 1) Gestáo democrática ou por liderança da escola e das salas de aula; 2) Diretor como líder da comunidade educativa; 3) Professor como líder dos alunos; 4) A escola como ambiente de satisfação das necessidades de seus membros; 5) Ensino baseado no aprendizado cooperativo; 6) Participação do aluno na avaliação de seu próprio trabalho; 7) Trabalho escolar de alta qualidade como produto de uma Escola de Qualidade (DIAS, 2000).

Além dos demais pontos de Glasser, já de antemão destaco aqui o primeiro por tratar de questáo tão cara à sociedade civil organizada nos anos 1980. A implementação da gestão democrática é uma das orientações do IAS para seus parceiros do setor público, porém, aos fundamentos e mecanismos dessa gestão, são atribuídos outros sentidos e significados, bastante diferentes daqueles que lhes deram origem (COSTA, 2011).

A divulgação dessas ideias no contexto brasileiro é associada aos projetos educacionais da ditadura militar.

Aparentemente, por exemplo, as ideias envolvidas no conceito de qualidade total podem ser remontadas àquilo que se convencionou chamar, naquela conjuntura, de tecnicismo educacional. Não por acaso, a grande ideóloga e propagadora da "filosofia" da qualidade total no Brasil, Cosete Ramos, foi autora, naquele período, de um conjunto de livretos intitulados Engenharia da Instrução, - lá, como aqui, montada na burocracia do Ministério da Educação e Cultura. (SILVA, 1996, p. 17). 
Silva (1996), chama a atenção para os cuidados necessários ao tratar de tal comparação, devido ao contexto de profundas mudanças no qual estão inseridas as áreas econômicas, sociais e políticas. Afirma que as armas da crítica devem ser diferentes daquelas empregadas no contexto da ditadura militar, pois este momento é eminentemente "[...] diferente das condições em que se enuncia o discurso educacional neoliberal" (SILVA, 1996, p. 17).

As justificativas dos meios político e empresarial para a adoção de medidas como essa, de orientação mercadológica, orientadas pela teoria da Escolha Pública, a partir da década de 1980, consistem em transformar questóes políticas e sociais em questôes técnicas. Essas ideias foram desenvolvidas com base na teoria da Escolha Pública, da escola de pensamento neoliberal Public Choice; seus parâmetros para a área pública provêm do modelo microeconômico.

Essas proposiçóes para a área educacional estão expressas nas formulaçóes de Milton Friedman (1985) em Capitalismo e liberdade. Sáo ideias que influenciaram a criação de mercados ou de quase-mercados educacionais em praticamente todo o mundo. No Brasil, têm influenciado inúmeras e diferentes formas de parcerias entre o Poder Público e o setor privado, como o objeto de análise deste texto.

Silva (1996), ao tratar do contexto no qual se inscreve a adoção da Gerência da Qualidade Total na Educação, nos anos 1990, aponta para o diagnóstico neoliberal sobre as questóes dos problemas sociais e educacionais. Para o autor, tais problemas "[...] não são tratados como questôes políticas, como resultado - e objeto - de lutas em torno da distribuiçấo desigual de recursos materiais e simbólicos e de poder, mas como questóes técnicas, de eficácia/ineficácia na gerência e administração de recursos humanos e materiais". (SILVA, 1996, p.18-19).

Estudos que tratam das soluçóes apresentadas para "problemas" semelhantes por governos de praticamente todo o mundo, amparados em medidas de orientação neoliberal, foram realizados por Dale (1995) na Austrália e Nova Zelândia, por Licínio Lima $(2005,2011)^{6}$ na Europa, por Aplle (2005) nos Estados Unidos e Inglaterra, e por Adrião e Peroni (2010) e Gentilli e Silva (1996) no Brasil, entre outros incontáveis estudos.

Neste contexto, Lima (2005, p. 81) adverte que

[...] os indivíduos e as organizaçóes de todo tipo, à semelhança das empresas, que são apresentadas 
como arquétipos da organização racional, inovadora e eficiente, passaráo a reger-se por princípios gerencialistas, comandados por doutrinas neocientíficas ou neotaylorianas da gestão.

A educação, por sua vez:

[...] passa a integrar-se numa indústria de serviços, num mercado de fornecedores em competiçáo. Espera-se que, em termos de resultados e de processos de gestáo a educaçáo possa, finalmente adaptar-se cabalmente à "economia do conhecimento" e enfrentar com sucesso os requisitos da competitividade internacional. Para esse efeito é necessário que ensine a competir, o que só será possível se, ela mesmo, aprender a competir através da prática da competição (LIMA, 2005, p. 81).

O Brasil, alinhado a essa tendência mundial, também adotou o discurso de ineficiência das instituiçóes públicas e desviou o foco dos problemas relacionados com o desempenho do sistema educacional a um problema de gerenciamento e controle das políticas educacionais pelas vias da avaliação. A medida de orientação empresarial, adotada por governos em diferentes partes do mundo, inclusive no Brasil, com a promessa de melhoria da qualidade da educação e dos sistemas públicos de ensino, é a já citada Gerência da Qualidade Total, a partir da década de 1990. De orientação empresarial, a Gerência da Qualidade Total na Educação é considerada

[...] uma nova estratégia que auxiliará as instituiçóes educacionais a melhorarem a qualidade do seu trabalho, através de um enfoque gerencial nas suas atividades administrativas e pedagógicas. Trata-se de um sistema gerencial que possibilitará a introdução de mudanças substanciais na escola, respeitando as opçóes e o modelo pedagógico adotado pela mesma (BARBOSA, 1994, p. 3).

Para se alcançar a qualidade total, os autores apresentam alguns aspectos, também chamados dimensôes da qualidade, denominados qualidade intrínseca, custo, atendimento, moral e segurança, com seus respectivos significados, assim 
definidos: qualidade intrínseca - refere-se às características do processo ou do produto que atendem o cliente, exemplificados por Barbosa como qualidade dos programas de reciclagem de professores; qualidade de uma aula; qualidade de um aluno formado; qualidade de um currículo, etc., custo - custo do produto ou serviço, como o custo dos programas de reciclagem para professores, custo de uma aula, etc.; atendimento - entrega no prazo certo, no local certo, na quantidade certa, como, por exemplo, o cumprimento do calendário escolar; moral - compreendida como as características que indicam o nível médio de satisfaçáo das pessoas do sistema, como moral dos professores, funcionários e especialistas; segurança - caracterizada pela segurança que o produto deve ter em relação ao usuário e ao funcionário da organização (BARBOSA, 1994).

Essas são algumas dimensóes da qualidade da educação na perspectiva da GQT. Conhecedores que somos dos vários significados atribuídos à palavra qualidade, na perspectiva da GQT, citamos Chiavenato, quem fez um apanhado de concepçóes de qualidade para alguns autores, resumindo-as e apresentandoas da seguinte forma:

[...] qualidade é o atendimento das exigências do cliente. Para Deming, "a qualidade deve ter como objetivo as necessidades do usuário, presentes e futuras". Para Juran, representa "a adequação à finalidade ou ao uso". Para Crosby, "é a conformidade com as exigências". Feigenbaum diz que ela é "o total das características de um produto ou serviço referentes a marketing, engenharia, manufatura e manutenção, pelas quais o produto ou serviço, quando em uso, atenderá às expectativas do cliente". (CHIAVENATO, 2003, p. 581).

Como se percebe, a ideia de qualidade apresentada relaciona-se à atividade administrativa nas organizações de produçâo capitalista, e não propriamente àquelas da área educacional. Há, como na maioria da história da educação, uma transposiçẫo de modelos de teorias das organizaçóes empresariais para esta. A tentativa de elaboração de uma teoria de organização específica da área educacional surgiu no Brasil, na década de 1980, com a gestâo democrática da educação. Porém, na década seguinte, vimos florescer a GQT, modelo de administração que é apropriado pelos sistemas de ensino, como a Secretaria de Estado da Educação de Minas Gerais, em 1991, e pelo próprio Ministério 
da Educação, na mesma época, sob a justificativa de melhoria da qualidade na educação. Entre os temas mais debatidos na atualidade, a defesa da qualidade na educação ocupa lugar de destaque.

Desde as declaraçôes dos organismos internacionais até as conversas de bar, passando pelas manifestaçôes das autoridades educacionais, as organizaçōes de professores, as centrais sindicais, as associaçôes de pais, as organizaçôes de alunos, os porta-vozes do empresariado e uma boa parte dos especialistas, todos coincidem em aceitar a qualidade da educaçáa ou do ensino como objetivo prioritário ou como um dos muito poucos que merecem consideração. (ENGUITA, 1996, p. 95).

Segundo Paro (2007, p. 15), nem sempre há consenso a respeito de um conceito, do que se entende por qualidade na educaçáo, assim como raramente tal conceito "[...] aparece explicitado de forma rigorosa". Esse autor argumenta que, "[...] quando se atenta para a importância social da educaçâo e para os enormes contingentes populacionais que as políticas públicas da área envolvem, mostra-se bastante preocupante essa ausência de um conceito inequívoco de qualidade" (PARO, 2007, p. 15), visto que:

[...] esta depende dos objetivos que se pretende buscar com a educação, quando estes não estão suficientemente explicitados e justificados pode acontecer de, em acréscimo à náo-correspondência entre medidas proclamadas e resultados obtidos, estar-se empenhando na realização dos fins errados ou não inteiramente de acordo com o que se pretende.

O reduzido rigor aplicado ao conceito de qualidade na educação deixa margem para todos falarem da temática, mas com conteúdos bastante diversificados. Muitas vezes, discursos sobre a qualidade são atrelados a resultados, como se pode extrair em artigo de Throsby e Gannicott (2005), "Qualidade da educação e eficácia do ensino escolar". No texto, os autores afirmam que, "[...] nos anos de 1970 e 1980, muitos governos perceberam que o rápido aumento das matrículas, ao longo da década de 1960 e início de 1970, talvez tivesse ocorrido ao preço de uma queda da qualidade do ensino" (THROSBY; GANNICOTT, 
2005, p. 160). As inúmeras justificativas, especialmente de cunho econômico, dadas pelos governos sobre restriçôes orçamentárias e objetivos educacionais deslocaram o foco do debate da quantidade para a qualidade, como explicam os autores: "[...] em conseqüência disso, pesquisadores e instâncias decisórias foram deixando aos poucos de enfatizar os aspectos quantitativos e passaram a se preocupar com a qualidade do ensino e com a insuficiência sobre os resultados deste" (THROSBY; GANNICOTT, 2005, p. 160). Gannicott e Throsby (2005) extraem desse contexto um conceito de qualidade composto de elementos como: a formação e a qualificação dos professores; a disponibilidade e a qualidade dos materiais didáticos, assim como dos materiais escolares; as normas relativas aos edifícios e às instalaçóes escolares; a saúde; o estado nutricional dos alunos e os conhecimentos adquiridos por eles antes de seu ingresso na escola; a natureza e a eficácia da administração e a infraestrutura da educação. Os autores deixam intocadas questóes socioeconômicas dos estudantes, por muitos consideradas como importante variante da qualidade educacional, ou seja, o debate não se dá no nível das desigualdades sociais, em torno das quais se dão as lutas de classes. Na perspectiva das desigualdades sociais, da luta de classes, Susin (2009) acena com uma ideia de qualidade extraída dos diversos autores que subsidiaram sua tese, afirmando:

[...] para se alcançar a qualidade na educação, a política educacional levada a efeito precisa tomar um conjunto de medidas nas quais se incluem náo somente o salário, mas a formação em serviço, o contato com novas visóes de educação e as suas metodologias, assessoria permanente, tempo para estudos, para planejamento e para discussão de problemas. (SUSIN, 2009, p. 283).

O campo aberto deixado pela falta de objetivos educacionais afeta a definiçấo da qualidade a ser alcançada pelo ensino, não só deixando margem para diversas interpretaçóes, como também espaço, em nome da qualidade, para a implementaçáo do pensamento hegemônico na educação, como se pode perceber com a GQT nessa área.

Não se trata de ampliar recursos para a educação, mas justificam-se as mudanças no discurso do pseudodesperdício de recursos humanos e materiais com a proposta de uma gestão eficiente, fazendo mais com menos. É, por exemplo, o que se nota com a aplicação dos preceitos da GQT na área 
educacional, pois não se deixa claro que qualidade se defende, e quais os meios humanos e materiais para alcançá-la; a impressão que se deixa é a de que cabe à gestão, pautada na racionalidade, conduzir à qualidade proclamada. No entanto, como se trata de medidas hegemônicas na atividade administrativa da organização social capitalista, a área educacional não ficou imune a tais medidas a partir do período apontado.

O aprofundamento do discurso favorável à GQT materializou-se em efetivas mudanças, a partir da década de 1980, auxiliando o conjunto de alternativas das quais o capital lançou mão para sair da crise. $\mathrm{Na}$ área educacional, a reforma deu-se com o cumprimento de uma agenda global para a educação iniciada na década de 1990, como pode ser percebido em inúmeros documentos internacionais sobre a formação de uma agenda comum em torno de compromissos e metas dos governos em consonância com a tal agenda global. Esses são alguns aspectos do contexto no qual emerge a GQT na educação no Brasil.

Segundo Silva (1996) apesar de toda a retórica da GQT em favor da participação dos "clientes" (a escolha do léxico nunca é inocente), e da definição dos objetivos e métodos educacionais a partir das necessidades e desejos dos "consumidores", dando uma ilusão de democracia, escolha e participação, a verdade é que a estratégia da qualidade total enquadra o processo escolar e educacional numa estrutura de pensamento e concepção que impede que se pense a educação de outra maneira. Sob a aparência de escolha e participação, a GQT "[...] impóe uma visão de educação e gerência educacional que fecha a possibilidade de se pensar de outra forma" (SILVA, 1996, p. 21). De fato, "[...] a verdadeira escolha consistiria em poder rejeitar a própria ideia de qualidade total, o que equivaleria a rejeitar toda a noção neoliberal de educaçáo" (SILVA, 1996, p. 21).

Esse ambiente é acentuado em alto grau pela emergência da denominada era da informação, e marcado também pelo uso indiscriminado da tecnologia da informação e pelos laços solitários unindo empresas, instituiçóes, sujeitos do mundo todo a redes de computadores. Sua racionalidade científica e tecnológica orienta a administração do centro do sistema por "controle remoto". Com base em uma administração gerencial e tecnológica, os propositores de políticas educacionais, nesse caso o IAS, encontram neste aparato conceitual as justificativas para difusão de ideias sobre qualidade na educação, conforme texto a seguir. 


\section{Planejamento e qualidade da educação nos programas de gestão do IAS}

O processo de elaboração do Planejamento, na perspectiva do IAS, apoiase na ideia corrente das novas tecnologias educativas, operadas pelas pesquisas do neocomportamentalismo de Skiner e pelo desenvolvimento do computer science, no qual há uma centralidade cada vez maior atribuída às máquinas nesse processo. Assim como o ensino e a aprendizagem, o planejamento nessa perspectiva é mais impessoal, mais controlável, mais microestruturado, mais capaz de autocorreção, ou seja, "[...] através do feedback dos círculos cibernéticos, que é um voltar atrás para modificar o próprio operado e obter melhores resultados" (CAMBI, 1999, p. 616).

Essa ideia está expressa nos materiais do IAS e fundamenta-se em um arranjo no qual as informaçóes oriundas da rotina das atividades escolares se processam em movimento circular: "[...] diagnosticar, planejar, executar, avaliar e diagnosticar... 'retroalimentar' novo planejamento" (IAS, 2007, p. 20). O arranjo é construído com base na análise gerencial feita a partir da checagem das informaçóes prestadas com as previstas no Plano de Metas da Secretaria de Educação e das Unidades Escolares. O cumprimento de todas as etapas com a checagem de informaçôes passa, conforme o IAS, a ideia de eficiência na gestão. $\mathrm{O}$ controle do movimento é visto como capaz de imprimir racionalidade ao processo educacional, levando, portanto, a melhores resultados. Senna (2008) justifica o movimento gerador do planejamento com os seguintes argumentos:

Na realidade, o maior problema é introduzir no dia-a-dia dos profissionais da educação a observância de quatro fases durante o processo educacional, praticadas de forma continuada: diagnóstico, planejamento, execução e avaliação, para novamente diagnosticar, planejar, executar e avaliar. Essa rotina precisa estar presente em todas as etapas e esferas do processo educacional, para que o aluno possa desenvolver, de fato, as competências cognitivas, produtivas, relacionais e afetivas, de forma a dar concretude aos quatro pilares educacionais: aprender a conhecer, a fazer, a conviver e a ser. (SENNA, 2008, p. 4). 
O alinhamento do IAS às propostas de educação expressas em documentos internacionais pode ser observado a partir dessa citação. Os pilares da educação citados acima estão definidos no Relatório Delors (DELORS, 1999) e são considerados, pela Unesco, como o caminho que conduz a "educaçáo ao longo da vida". A ideia de planejamento expressa nos documentos instrucionais de gestão do IAS, portanto, teria o papel de conduzir a educaçâo para constituir, "[...] por assim dizer, uma 'sociedade educativa', ao mesmo tempo 'sociedade aprendente", em plena consonância com tal documentaçáo, "[...] emanada de importantes organismos multilaterais" que, por sua vez, atribuem à "[...] educaçáo o poder de sustentação da competitividade" (SHIROMA; MORAES; EVANGELISTA, 2007, p. 56).

Alguns termos utilizados pelo IAS para assinalar elementos e mecanismos necessários à materialização da gestão, como retroalimentação/realimentação ou feedback, são usados para designar esse movimento circular, conforme já expresso, e indicam uma transposiçấo de conceitos da Teoria de Sistemas Abertos e cibernética para a área da educação. Por sua vez, esta também absorve outros termos, como sistema, rede, etc., mecanismos essenciais ao funcionamento da gestâo dos Programas do IAS.

Encontrei aproximação entre esses conceitos e áreas que deram origem ao novo paradigma do conhecimento a partir da segunda metade do século XX e que atualmente se encontram nas bases do pensamento complexo (MORIN, 2000), em contraposição ao conhecimento científico fundado no pensamento cartesiano ou mecanicista (CAPRA, 2006). Vale ressaltar que Morin e Capra são teóricos que não se aproximam do pensamento dialético, no entanto, são citados porque auxiliam a compreensão dos Programas em análise.

A ideia de complexidade considera que a inter-relação dos agentes em um sistema complexo é dinâmica, não linear, aberta, imprevisível, caótica, sensível às condiçôes iniciais. Como parte do pensamento complexo, o conceito de retroalimentação/realimentação ou feedback é considerado um dispositivo responsável pela eficiência e eficácia da gestão nos programas em estudo. A ideia é que " [...] as variaçôes no ambiente devem determinar variaçóes no sistema e as correçôes do sistema são possíveis graças à de um dispositivo especial que é o 'feedback' ou retroalimentação" (ALONSO, 1988, p. 77-78). Capra (2007) afirma que esse conceito, formulado por Norbert Wiener, está expresso no próprio significado de cibernética e pode ser compreendido como 
[...] um arranjo circular de elementos ligados por vínculos causais, no qual uma causa inicial se propaga ao redor das articulaçóes do laço, de modo que cada elemento tenha um efeito sobre o seguinte, até que o último realimenta (feedbacks) o efeito sobre o primeiro elemento do ciclo. A conseqüência desse arranjo é que a primeira articulação (“entrada”) é afetada pela última ("saída"), o que resulta na auto-regulação de todo o sistema, uma vez que o efeito inicial é modificado cada vez que viaja ao redor do ciclo. [...] Num sentido mais amplo, a realimentação passou a significar o transporte de informaçóes presentes nas proximidades do resultado de qualquer processo, ou atividade, de volta até sua fonte. (CAPRA, 2007, p. 59).

Ao criticar o uso indiscriminado da cibernética no mundo moderno, Morin (2005) argumenta que, retirando a sua vertente fecunda, “[...] a cibernética serviu para a redução de tudo que é social, humano, biológico à lógica unidimensional das máquinas artificiais” (MORIN, 2005, p. 110). Com base nesse conceito, que em muitos aspectos se apresenta "mecanicista", de uma pretensa racionalidade, percebo muita proximidade entre essa área e a "finalidade" do Sistema Ayrton Senna de Informação (Siasi) no que se refere à análise gerencial para elaboração e execução do planejamento educacional, considerado tema relevante para o "sucesso" da organização escolar. Nessa perspectiva, o planejamento aparece, portanto, como o recurso mais adequado para manter um alto grau de racionalidade, por permitir um processo de decisão conveniente à organização, conforme defende Simon (1964).

O uso do conceito de cibernética no contexto educacional remete à análise de Leff (2006), teórico filiado ao pensamento dialético, acerca do paradigma da complexidade. A incompatibilidade entre as origens do conceito e sua aplicação às Ciências Humanas e Sociais é focalizada pelo autor:

[...] como mostra a epistemologia crítica, os conceitos mecanicistas e organicistas têm funcionado como obstáculos epistemológicos na construção de conceitos que correspondem à organização da ordem simbólica e social. [...] ao estender os princípios organizadores da vida e dos processos ecológicos para a sociedade humana, se desconhece a especificidade das ordens históricas e 
simbólicas, do poder, do desejo e do conhecimento. (LEFF, 2006, p. 29).

Com a aplicação do conceito à área da educação, subentende-se que conseguirá eficiência e eficácia na gestáo. Difunde-se a ideia de um sistema autorregulável em que, corrigidas todas as etapas do processo educacional, se terá o funcionamento "perfeito" do sistema, segundo o IAS, para uma educação pública de qualidade.

Como já afirmei, a questão da qualidade do ensino é um tema recorrente nos últimos tempos nos discursos pedagógicos e nas plataformas políticas. Não surpreende o fato de a temática ocupar lugar especial nos materiais de gestáo do IAS, os quais apontam a qualidade como o fim último da educaçáo. Assim como outros conceitos abordados nos textos do IAS, não há uma definição clara da qualidade defendida para a educação pública brasileira. Situação análoga é analisada por Contreras (2002) acerca da profusão da ideia de autonomia de professores, mas que pode ser aplicada a qualquer outra área, inclusive à qualidade da educação. A profusão dessas ideias, segundo Contreras, está se dando:

Sobretudo, na forma de slogans, que como tal se desgastam e seus significados se esvaziam com o uso freqüente. Podese dizer que, por serem slogans, são utilizados em excesso para provocar uma atração emocional, sem esclarecer nunca o significado que lhes quer atribuir. Funcionam assim como palavras com aura, que evocam idéias que parecem positivas e ao redor das quais se pretende criar consenso e identificação. Porém, é provável que parte do êxito dos slogans em geral, como o da autonomia de professores em particular, resida em que na verdade escondem diferentes pretensóes e significados, em que diferentes pessoas estejam entendendo ou querendo dizer coisas diversas com as mesmas palavras, embora aparentemente todos digam o mesmo. (CONTRERAS, 2002, p. 23).

O sentido de slogan como palavras com aura, segundo Contreras, em alguns casos é muito mais evidente, como se exemplifica com o tema qualidade da educação. Mesmo sendo um pouco extensa, vale a pena reproduzir a análise de Contreras acerca do referido tema. $\mathrm{O}$ autor afirma que, "[...] atualmente, 
todo programa, toda política, toda pesquisa, toda reivindicação educativa é feita em nome da qualidade. É evidente que todos estão de acordo com tal aspiração" (CONTRERAS, 2002, p. 23). No entanto, defende o autor, "[...] citá-la sem mais nem menos é às vezes um recurso para não defini-la, ou seja, para não esclarecer em que consiste, que aspirações traduz" (CONTRERAS, 2002, p. 23). Contreras argumenta que:

Remeter à expressão "qualidade da educação", em vez de explicitar seus diversos conteúdos e significados para diferentes pessoas em diferentes posiçôes ideológicas, é uma forma de pressionar para um consenso sem permitir discussáo. Evidentemente esse é um discurso que pode ser utilizado por quem tem poder para dispor e difundir o slogan como forma de legitimar seu ponto de vista sem discuti-lo. Por que tem poder para repeti-lo várias vezes sem esclarecer nada. [...] Um recurso que, além disso, se impóe a todos: uma vez que a referência à qualidade transformou-se na forma de falar, ninguém pode abandoná-la, ninguém pode dizer que sua pretensão não é a qualidade da educação. (CONTRERAS, 2002, p. 23-24).

Essa exposição auxilia a compreensão do uso recorrente da temática qualidade da educaçáo nos textos do IAS. Assim como outros temas, este permeia seus materiais impressos, nos quais a sistemática de acompanhamento e o cumprimento de metas, entre outros, são indicativos de qualidade. Em nome da qualidade, justificam-se até mesmo a própria criação do IAS e sua atuação na área educacional. $\mathrm{O}$ poder de que desfruta o Instituto autoriza seus representantes a falar, por exemplo, em nome de uma pretensa qualidade da educação, sem, no entanto, se preocuparem com a sua definiçáo. Como já disse anteriormente, neste momento particular do capitalismo, o Terceiro Setor "emergente" tem o controle da concepção, elaboraçáo, implementação e avaliação de inúmeras políticas públicas sociais, portanto, produz seus slogans em torno de algumas palavras "aura" ou "mágicas", que, como o "canto da sereia", encantam o poder público, a área empresarial, o voluntariado e até mesmo inúmeros e desavisados educadores.

Ainda sobre a questão da qualidade, Freitas (2003) também faz excelente análise da profusão desse tema na atualidade. Segundo ele, "[...] tem-se dito 
que o papel da escola em nossa sociedade é prover o ensino de qualidade para todos os estudantes, indistintamente" (FREITAS, 2003, p. 14). Portanto, independentemente das condiçóes da sociedade, "[...] cabe à escola encontrar os meios de ensinar tudo a todos" (FREITAS, 2003, p. 14). Para esclarecer a questão, o autor analisa o papel da escola à luz de duas tendências: a liberal e a socialista. Na primeira, "[...] propôem que a escola ensine todos os estudantes, independentemente do nível socioeconômico destes" (FREITAS, 2003, p. 14). Nessa versão, "[...] a desigualdade social deve ser compensada no interior da escola pelos recursos pedagógicos de que esta dispóe" (FREITAS, 2003, p. 16) a isso se chama equidade. Conforme Freitas,

[...] para os que olham para a eficácia da escola ${ }^{7}$ na perspectiva ingênua da eqüidade, o que resta a fazer é estudar e divulgar quais fatores intrínsecos à escola (recursos pedagógicos e escolares, tamanho da escola, estilo de gestáo, treinamento do professor etc.) afetam o aumento da qualidade da aprendizagem (proficiência do aluno), apesar das influências do nível socioeconômico sobre o qual, dizem, nada se pode fazer. Este é o sonho liberal: independentemente do nível socioeconômico (ou, como se diz, descontados os efeitos do nível socioeconômico) todos os alunos deveriam aprender em um nível de domínio elevado. (FREITAS, 2003, p. 17).

A versão socialista, para Freitas (2003, p. 18), “[...] não discorda que a escola deva ensinar todos os alunos em um nível elevado de domínio, mas atacará o problema por outro ângulo", qual seja: "[...] pela necessidade da eliminação dos desníveis socioeconômicos e da distribuição do capital cultural e social, o que supóe discutir como se acumulam outras formas de capital - o econômico, por exemplo".

Não encontrei essa discussão nos materiais instrucionais do IAS. Neles, a escola não é apresentada como uma organização social, histórica e situada em determinado contexto político, social, cultural, econômico, etc., cuja atividade administrativa expresse as contradiçóes da organização social capitalista. $\mathrm{Na}$ concepção de escola apresentada pelo IAS, a ideia de planejamento nem sequer aponta para a elaboração de um marco referencial, com um debate político e filosófico acerca de concepçóes de sociedade e de homem aos quais a funçấo social da escola se destina. Isso certamente requer, em uma perspectiva democrática, 
interlocução entre poder público e sociedade, com ampla participação de pais, alunos, educadores, representaçóes acadêmicas, científicas e sindicais.

\section{Considerações finais}

Retomando as questốes que nortearam o texto, infere-se que os argumentos apresentados pelo IAS sobre a ineficácia do Estado na execução de políticas sociais, em especial a educação, são tomados de empréstimo do pensamento hegemônico (neoliberal e da Terceira Via), que têm por fundamentos os princípios da macroeconomia, da "solidariedade" e do "voluntariado". Essas correntes acusaram o Estado do bem-estar social pela crise do capital e propóem alternativas diferentes ao papel do Estado, como as privatizaçóes e o Terceiro Setor, respectivamente. Nesse sentido, além de substituir o papel do Estado na elaboração, acompanhamento, avaliação e controle de resultados da educação pública, o IAS constitui-se em uma entidade singular do Terceiro Setor, um intelectual orgânico do capital. Essa afirmaçáo se baseia na atuação desse Instituto tanto junto ao Poder Público quanto em suas relaçóes com o grande capital nacional e estrangeiro. Deste, recebe doações financeiras; com o Poder público, faz parcerias, abrindo possibilidades de negócios para vários "parceiros" do setor privado fornecerem produtos com exclusividade, como também estimulando a captação de recursos da comunidade escolar por meio da implementação da "autonomia financeira" (GUTIERREZ; COSTA, 2011). Os organismos internacionais e os Conselhos que a presidente do Instituto integra podem ser um indicativo do poder que essa entidade desfruta junto ao Estado e ao grande capital na atualidade.

A ideia de qualidade da educação presente nos materiais de gestáo do IAS encaminhados para implementação pelo Poder Público não apresenta originalidade. É, ao contrário, emprestada da teoria das organizaçóes e, nesse caso, da Gerência da Qualidade Total (GQT) e das teorias que lhe dáo sustentação. A definição de muitos conceitos que, segundo o IAS, conduzem à qualidade da educação, expostos nos materiais analisados e presentes no texto, é extraída de dicionários de língua portuguesa, ou simplesmente os conceitos são apresentados sem uma definição. Essa ausência de definição de conceitos levou à busca de aproximação entre qualidade da educação difundida nos materiais do IAS e a teoria das organizaçóes empresariais, nesse caso, a GQT. Pode-se afirmar que a ideia de qualidade da educação difundida pelo 
IAS é tomada de empréstimo do meio empresarial. Educação e mercadoria são equiparadas.

Por fim, pode-se dizer que a defesa da qualidade da educaçáo constitui, para o Instituto, um recurso de poder, um slogan, uma palavra com "aura" (CONTRERAS, 2002), da qual lança mão para seduzir o setor privado, com vistas ao financiamento, e o público para financiar e adotar seu projeto de educação. Em meio ao crescimento do Terceiro Setor, pós-reforma do Estado na década de 1990, há milhares de ONGs disputando recursos públicos e privados no mercado, necessários à sua sobrevivência. O produto (informações privilegiadas e em tempo real dos resultados da educaçáo) possibilita a legitimidade do IAS na disputa por recursos junto ao grande empresariado e ao Estado. Diante da impossibilidade de privatização da Educação Básica, adota-se a lógica do mercado por dentro do público. Nessa lógica, não há menos investimento na educação, mas uma nova metodologia na utilização de recursos públicos. A ausência tanto de consenso em torno de um conceito de qualidade na educação quanto de rigor no tratamento de tal conceito é bastante preocupante (PARO, 2007), pois possibilita a incursão dos interesses do capital na educação, conforme apresenta este estudo.

\section{Notas}

1 Diretoria: a diretoria do Instituto Ayrton Senna é formada pela família do piloto, e Viviane Senna é a presidente do IAS desde a fundação em 1994. Conselho Consultivo: formado por expoentes dos vários setores da sociedade, o Conselho Consultivo do IAS contribui para a realizaçáo da missão do Instituto junto às novas geraçóes. Fazem parte do Conselho: Antonio Maciel Neto - presidente da Suzano Papel e Celulose; Antonio Roberto Beldi - presidente da Splice do Brasil Telecomunicaçóes e Eletrônica S. A.; Arthur Briquet Jr. - presidente da Gallery/Oggi/Bricon/Artell Editora; Chico Pinheiro - jornalista da Rede Globo de Televisão; David Barioni Neto - presidente da TAM; Élcio Aníbal de Lucca - presidente de Assuntos Corporativos da Serasa; Gustavo Ioschpe - economista, fundador-presidente e sócio-proprietário da G7 Cinema; Ives Gandra da Silva Martins - jurista; Jackson Schneider - presidente da Anfavea; Juscelino Fernandes Martins VP da Martins Comércio e Serviços de Distribuição S.A.; Luiz Fernando Furlan - Presidente da Sadia S.A.; Osmar Elias Zogbi - presidente da EAZ 
Participaçôes Ltda.; Walter Piacsek - VP do The Boston Consulting Group. Disponível em: <http://senna.globo.com/institutoayrtonsenna>. Acesso em: 31 jul. 2008.

2 Entrevista concedida pela presidente do IAS à revista digital Ecofenix. Disponível: <http://ecofenix.com>. Acesso em: 26 fev. 2008.

3 Ao final do dia, o IAS recebeu R 5.425 milhóes nesse Fórum.

4 Disponível em: < http://senna.globo.com/institutoayrtonsenna. Acesso em: 16 out. 2007.

5 Prêmio Nobel, desenvolveu uma detalhada teoria dinâmica para descrever o comportamento desses sistemas (CAPRA, 2007).

6 Palestra proferida por Licínio Lima no XXV Seminário Brasileiro; II Congresso Ibero-Americano de Política e Administração da Educação; Jubileu de Ouro da Anpae (1961-2011), realizado em Sáo Paulo, abril de 2011.

7 Freitas discute a lógica da escola e nesse texto afirma que a tese da escola eficaz, com equidade, se afirmou em contraposição ao susto que Coleman e seus colegas (1966) deram ao elaborar um relatório concluindo que os achados de suas pesquisas nos Estados Unidos lhes permitiam questionar se a escola fazia diferença na aprendizagem do aluno, já que o nível socioeconômico era mais determinante dos resultados desse aluno do que os recursos pedagógicos que poderiam ser arregimentados para prover sua aprendizagem. Afirma que, mesmo com correçóes introduzidas nas conclusôes de Coleman, estudos que se seguiram concluíram que "[...] não se pode transferir o problema da aprendizagem para a adequação ou não dos 'recursos pedagógicos da escola', ocultando a diversidade de 'nível sócio-econômico dos alunos' gerada no âmbito de uma sociedade injusta. [...] apesar do nível socioeconômico dos alunos, a escola pode fazer alguma diferença nessa relação, já que não é unidimensional e determinista" (FREITAS, 2003, p. 14-15). 


\section{REFERÊNCIAS}

ADRIÃO, Theresa; PERONI, Vera. Análise das consequências de parcerias firmadas entre municipios brasileiros e o Instituto Ayrton Senna para a oferta educacional. Campinas: Unesp, 2010. (Relatório de Pesquisa).

ALONSO, Myrtes. O papel do diretor na administraçáo escolar. 6. ed. Rio de Janeiro: Bertrand Brasil, 1988.

ANTUNES, Ricardo. Os sentidos do trabalho: ensaio sobre a afirmaçấo e a negação do trabalho. São Paulo: Boitempo, 2003.

APPLE, Michael W. Para além da lógica do mercado: compreendendo e opondo-se ao Neoliberalismo. Traduçáo de Gilka Leite Garcia. Rio de Janeiro: DP\&A, 2005.

BAHIA. Secretaria da Educação. Fundação Luís Eduardo Magalhães. Gerenciando a escola eficaz: conceitos e instrumentos. Salvador: Secretaria da Educação, 2000.

BARBOSA, Eduardo Fernandes et al. Gerência da Qualidade Total na Educação. Belo Horizonte, MG: Fundação Christiano Ottoni/UFMG, 1994.

CAPRA, Fritjof. O ponto de mutação: a ciência, a sociedade e a cultura emergente. Tradução de Álvaro Cabral. 27. ed. São Paulo: Cultrix, 2006.

CAPRA, Fritjof. A teia da vida. São Paulo: Cultrix, 2007.

CAMBI, Franco. História da Pedagogia. Tradução de Álvaro Lorencini. São Paulo: Editora da UNESP, 1999.

CHIAVENATO, Idalberto. Introdução à Teoria Geral da Administração: uma visão abrangente da moderna administração das organizaçóes. 7. ed. Rio de Janeiro: Elsevier, 2003.

CONTRERAS, José. A autonomia de professores. Tradução de Sandra Trabudo Valenzuela. São Paulo: Cortez, 2002.

COSTA, Marilda de Oliveira. Concepçóes de gestão nos programas do Instituto Ayrton Senna no contexto de alteraçóes no papel do Estado e da sociedade civil. 2011. 353 p. Tese (Doutorado em Educação) - Universidade Federal do Rio Grande do Sul, Porto Alegre, 2011. 
DALE, Roger. O marketing do mercado educacional e a polarização da Educação. In: GENTILI, Pablo (Org.). Pedagogia da exclusão: crítica ao neoliberalismo em educação. 9. ed. Petrópolis: Vozes, 1995. p. 137-168 (Coleção Estudos Culturais em Educação).

DELORS, Jacques et al. Educação um Tesouro a Descobrir: relatório para UNESCO da Comissão Internacional sobre educação para o século XXI. Brasília, DF: UNESCO; MEC; Cortez Editora, 1999.

DIAS, Miriam Fernandes Xavier. Qualidade na Educação. Revista Vértices, Rio de Janeiro, RJ, ano 3, n. 1, p. 7-10, 2000.

ENGUITA, Mariano Fernandez. O discurso da qualidade e a qualidade do discurso. In: GENTILI, Pablo A. A.; SILVA, Tomaz Tadeu da (Org.). Neoliberalismo, Qualidade Total e Educação. 4. ed. Petrópolis: Vozes, 1996. p. 93-110.

FERNANDES, Rubem César. Privado, porém público: o Terceiro Setor na América Latina. 3. ed. Rio de Janeiro: Relume-Dumará, 1994.

FÉLIX, Maria de Fátima Costa. Administração escolar: um problema educativo ou empresarial? São Paulo: Cortez, 1989.

FREITAS, Luís Carlos de. Ciclos, seriação e avaliação: confronto de lógicas. São Paulo: Moderna, 2003.

FRIEDMAN, Milton. Capitalismo e liberdade. Tradução de Luciana Carli. 2. ed. São Paulo: Nova Cultural, 1985. (Coleção Os Economistas).

GOMES, Hélio. Transformação do Paradigma Gerencial. Revista Dois Pontos. Belo Horizonte, v. 3, n. 27, p.52-77, jul./ago. 1996.

GUTIERRES, Dalva V. G.; COSTA, Marilda de Oliveira. O financiamento e o controle social dos recursos da educação no contexto das parcerias firmadas entre o Instituto Ayrton Senna (IAS) e municipios brasileiros. Recife/PE: Anpae, 2011. (no prelo).

HARVEY, David. Condição pós-moderna. 4. ed. São Paulo: Loyola, 2003.

INSTITUTO AYRTON SENNA (IAS). Educação para um Brasil vencedor. São Paulo, 2001.

INSTITUTO AYRTON SENNA (IAS). Rede Vencer. Formação Continuada de Diretores, São Paulo: 2005. (digitado). 
INSTITUTO AYRTON SENNA (IAS). Sistemática de Acompanhamento Gestão Nota 10, São Paulo, 2007.

IOSCHPE, Evelyn Berg. 3o Setor: desenvolvimento social sustentado. 2. ed. Rio de Janeiro: Paz e Terra, 2005.

LEFF, Enrique. Aventuras da epistemologia ambiental: da articulação das ciências ao diálogo de saberes. Tradução de Gloria Maria Vargas. Rio de Janeiro: Garamond, 2004.

LEFF, Enrique . Epistemologia ambiental. Tradução de Sandra Valenzuela. 4. ed. São Paulo: Cortez, 2006.

LIMA, Licínio C. Cidadania e Educação: adaptação ao mercado competitivo ou participação na democratização da democracia? Educação, Sociedades e Culturas, São Paulo, n. 23, p. 71-90, 2005.

MORIN, Edgar. Ciência com consciência. 9. ed. Rio de Janeiro: Bertrand Brasil, 2005.

MORIN, Edgar. Complexidade e liberdade. Ensayos Thot: associação Palas Athenas, São Paulo, n. 67, p. 12-19, 1998.

MORIN, Edgar; MOIGNE, Jean-Louis Le. A inteligência da complexidade. Tradução de Nurimar Maria Falci, São Paulo: Peirópolis, 2000.

NEIVA, Evando. IV Congresso Pitágoras Qualidade em Educação. Dois Pontos, Belo Horizonte, v. 3, n. 27, p. 78-97, jul./ago., 1996.

OLIVEIRA, Miguel Darcy de. Prefácio. In: FERNANDES, Rubem César. Privado, porém público: o Terceiro Setor na América Latina. 3. ed. Rio de Janeiro: Relume-Dumará, 1994.

PARO, Vitor Henrique. Gestão escolar, democracia e qualidade do ensino. São Paulo: Ática, 2007.

SENNA, Viviane. Um meio para o Sucesso. Revista Educação em Cena, São Paulo, 2008.

SHIROMA, Eneida Oto; MORAES, Maria Célia Marcondes de; EVANGELISTA, Olinda. Política Educacional. 4. ed. Rio de Janeiro, RJ: Lamparina, 2007. 
SILVA, Tomas Tadeu da. A "nova" direita e as transformaçóes na pedagogia da política e na política da pedagogia. In: GENTILI, Pablo A. A.; SILVA, Tomaz Tadeu da (Org.). Neoliberalismo, Qualidade Total e Educação. 4. ed. Petrópolis: Vozes, 1996

SIMON, Herbert A. El comportamiento administrativo. 2. ed. Valencia, Espanha: Aguilar, 1964.

SUSIN, Maria Otília Kroeff. A qualidade na Educação Infantil em Porto Alegre: estudo de caso em quatro creches conveniadas. 2009. $363 \mathrm{f}$. Tese (Doutorado em Educação) - Universidade Federal do Rio Grande do Sul, Porto Alegre, 2009.

THROSBY, David; GANNICOTT, Ken. Qualidade da educação e eficácia do ensino escolar. In: DELORS, Jacques (Org.). A educação para o século XXI: questôes e perspectivas. Tradução de Fátima Murad. Porto Alegre: Artmed, 2005. 
Tercer sector, teorias de las organizaciones y calidad en la educación

\section{Resumen}

Este artículo es parte de estudios realizados en el doctorado en Educación y tiene como objetivo discutir la calidad de la educación presentada en los materiales instructivos de una entidad del Tercer Sector que viene influyendo en las políticas educativas en las diferentes esferas de gobierno desde finales de 1990 en Brasil. Es de abordaje cualitativo y consistió en el análisis de los documentos emitidos por la dicha entidad y por el poder público de una ciudad brasileña. La idea de calidad expresa en estos materiales es tomada de préstamo de las teorías de las organizaciones empresariales, como la Gestión de la Calidad Total. En la actualidad, se ha hecho evidente que la polisemia de las ideas involucradas en el término calidad de la educación permite varias interpretaciones y facilita los discursos o consignas sobre el tema. A pesar de la relevancia de estos discursos, los materiales analizados muestran que la defesa de la calidad se ha dado en discursos o en consignas, como um recurso de poder, sin una definición clara y objetiva de la calidad que aboga por la educación brasileña.

Palabras claves: Tercer Sector. Administración de la educación. Calidad Total.

\section{Third sector, theory of organizations and quality in education}

\section{Abstract}

This paper is an integral part of studies carried out during a doctoral course in education and discusses the concept of quality of education as presented in instructional materials used by a third sector institution that has influenced educational policies in Brazil at different government levels since the 1990's. The study uses a qualitative approach to analyze documents produced by both the institution and municipal government authorities. The concept of quality presented in these materials was taken from business theories such as Total Quality Management. The study found that the polysemy of ideas involved in the term quality of education allows several interpretations and facilitates discourses or slogans about the theme. Despite the relevance of these discourses, the materials analyzed show that the defense of quality is found in discourse and slogans, without a clear and objective definition of the kind of quality that should be advocated for Brazilian education.

Keywords: Third Sector. Education Management. Total Quality. 
Marilda de Oliveira Costa

E-mail: marildacosta@hotmail.com

Recebido em: 27/2/2012

Versáo final recebida em: 27/9/2012

Aprovado em: 9/11/2012 